\title{
Statistical Analysis of Shape of Auricular Concha for Mass Customization of OTC Hearing Aids
}

\author{
Análisis Estadístico de la Forma de la Concha Auricular \\ para la Personalización Masiva de Audífonos de Venta Libre
}

Zhaohua Zhu' ${ }^{1}$ Jun Yao'; Bingyi Cao² ${ }^{2}$ Kexuan Zhou' ${ }^{1}$ \& Xiaomin $\mathrm{Ji}^{3}$

ZHU, Z.; YAO, J.; CAO, B.; ZHOU, K. \& JI, X. Statistical analysis of shape of auricular concha for mass customization of OTC hearing aids. Int. J. Morphol., 39(6):1655-1662, 2021.

SUMMARY: A detailed data of shape of auricular concha is currently not available. Therefore, this study constructed a framework to statistically analyze the shape of the auricular concha based on a database of 3D scanned images. The 3D models of the auricular concha from 308 study participants are converted into compatible NURBS surfaces generated through 795 data points to perform a requisite statistical analysis. Subsequently, the shape of the auricular concha of the participants is grouped into 29 clusters with a modified hierarchical clustering algorithm. Finally, a wear trial and simulation test are carried out to validate the wear comfort of a designed OTC hearing aids based on the average shape of each cluster. The experimental results show that the average shape obtained as per the cluster is capable of representing the common geometric properties of their corresponding members, and could thus be used as a reference in designing mass-customized OTC hearing aid. The method in this study is superior to conventional methods that rely on sparse results for shape analysis because it takes into account the intricate geometric shape of the auricular concha. The quantitative description of conchal morphometry will be beneficial for plastic surgeons, and for the ergonomic design of ear-related products.

KEY WORDS: Conchal Morphometry; Shape Clustering; Over the Counter Hearing Aids; Mass customization.

INTRODUCTION

One of the most intricate body parts to model aside from the head is the auricle of the ear. Detailed information of the morphology, dimensions, location, and asymmetry of normal auricles is essential for diagnosing congenital abnormalities and syndromes, conducting forensic investigations, and ergonomically designing ear-related products (Coward et al., 2000; Purkait \& Singh, 2007; Tatlisumak et al., 2015). Regardless of ethnicity, the literature shows that the mean dimensions of the auricle are larger in males than females, as evidenced by the numerous anthropometric studies that focus on the auricles of different ethnic groups, such as the Chinese (Liu, 2008; Wang et al., 2011; Yu et al., 2015; Zhu et al., 2017; Zhao et al., 2018; Fan et al., 2019), Koreans (Jung \& Jung, 2003; Kang et al., 2006; Han et al., 2010; Lee et al., 2018), Malaysians (Kumar \& Selvi, 2016), Indians (Purkait \& Singh; Sharma et al., 2007; Purkait, 2013; Singhal et al., 2016), Sudanese Arabs
(Ahmed \& Omer, 2015), Italians (Russo, 1998; Ferrario et al.,1999; Sforza et al., 2009), and Britons (Coward et al.; Alexander et al., 2011). Moreover, it is worth noting that there are significant differences in the dimensions of the ears of those in different nations and of different ethnicities (for e.g., the Europeans have larger dimensions in comparison to Asians), thus suggesting that ear-related products for the Chinese population should not be designed based on the dimensions and shape of the ears of those who are not Chinese. Hence, it is important to establish an anthropometric database for specific racialized groups.

Jung \& Jung and Liu, measured the length of the auricle of Korean and Taiwanese subjects, respectively. They then analyzed the length of earphones obtained from their local market and provided suggestions for enhanced ergonomic fit. They found that the length of the ear

\footnotetext{
${ }^{1}$ School of Architecture \& Design, China University of Mining and Technology, Xuzhou 221116, China.

${ }^{2}$ School of Art and Design, Jiangsu Vocational Institute of Architecture Technology, Xuzhou 221116, China.

${ }^{3}$ School of Art and Design, Xi'an University of Technology, No. 5 Jinhua Road, Xi' an 710048, China.

This study was supported by the National Natural Science Foundation of China (Grant Number: 52005498) and the Fundamental Research Funds for the Central University (Grant Number: 2020SK15).
} 
connection of wearable and non-slip earphones does not accommodate the ear canal and auricular concha, thus, other dimensions and shapes of the auricular concha should be considered. Ji et al., (2017) categorized the shape of the auricular concha of Chinese men and women into different groups based on seven characteristic distances related to the auricular concha and five characteristic points of each auricular concha as the basis for the ergonomic design of ear. The previous studies mainly inclined to assess ear length and width, lobule length and width, conchal length and width, and the types of lobule (attached, intermediate, and free types). Nevertheless, these univariate measures of ear size in the literature have limited applicability for current designs of ear-related products because they have neglected the shape of the outer ear or auricular concha. To the best of our knowledge, there are no studies in the literature that have provided a comprehensive introduction on the different shapes of the auricular concha, even though the auricular concha is an essential part of the outer ear. This paper therefore focuses on the difference in shape and different classifications of the auricular concha, specifically of young Chinese people since race and ethnicity determine the dimensions of the ear-related products.

The remainder of this paper is organized as follows. A discussion on the collected three-dimensional (3D) ear impressions of 308 young Chinese adults is provided, followed by an elaboration on the proposed methods used to extract the data points and reconstruct the surface of the auricular concha. Furthermore, the modification of a hierarchical clustering algorithm is discussed to assess the similarities in the shape of the auricular concha which is used to categorize the shape of the auricular concha of the participants into several groups. Then, the average shape of the auricular concha in each cluster is calculated as a reference for OTC hearing aid designs. Subsequently, the feasibility of the classification result is demonstrated by wear comfort and a finite element simulation analysis. Finally, some concluding remarks are made and future research directions are recommended.

\section{MATERIAL AND METHOD}

Samples. The study sample consisted of 308 healthy young Chinese volunteers (141 females and 167 males), between the ages of 18 and 28 years old. The mean age of the females is $21.3 \pm 2.6$ years old and that of the males is $20.3 \pm 2.0$ years old. All of the participants are students in universities located in different provinces of China. Any participant with a previous history of craniofacial trauma, congenital anomalies, or surgery were excluded from participation in the study. Impressions of the left ear of the 141 females and 169 males were made by using silicone putty material and then the impressions were scanned by using an Einscan-S 3D scanner with an accuracy of $0.1 \mathrm{~mm}$ and EinScan-V1.7.1 software (Fig. 1).

The study was approved by the Ethics Committee of the institution of the first author. The subjects provided written informed consent after they were given details of the experiment and their rights.
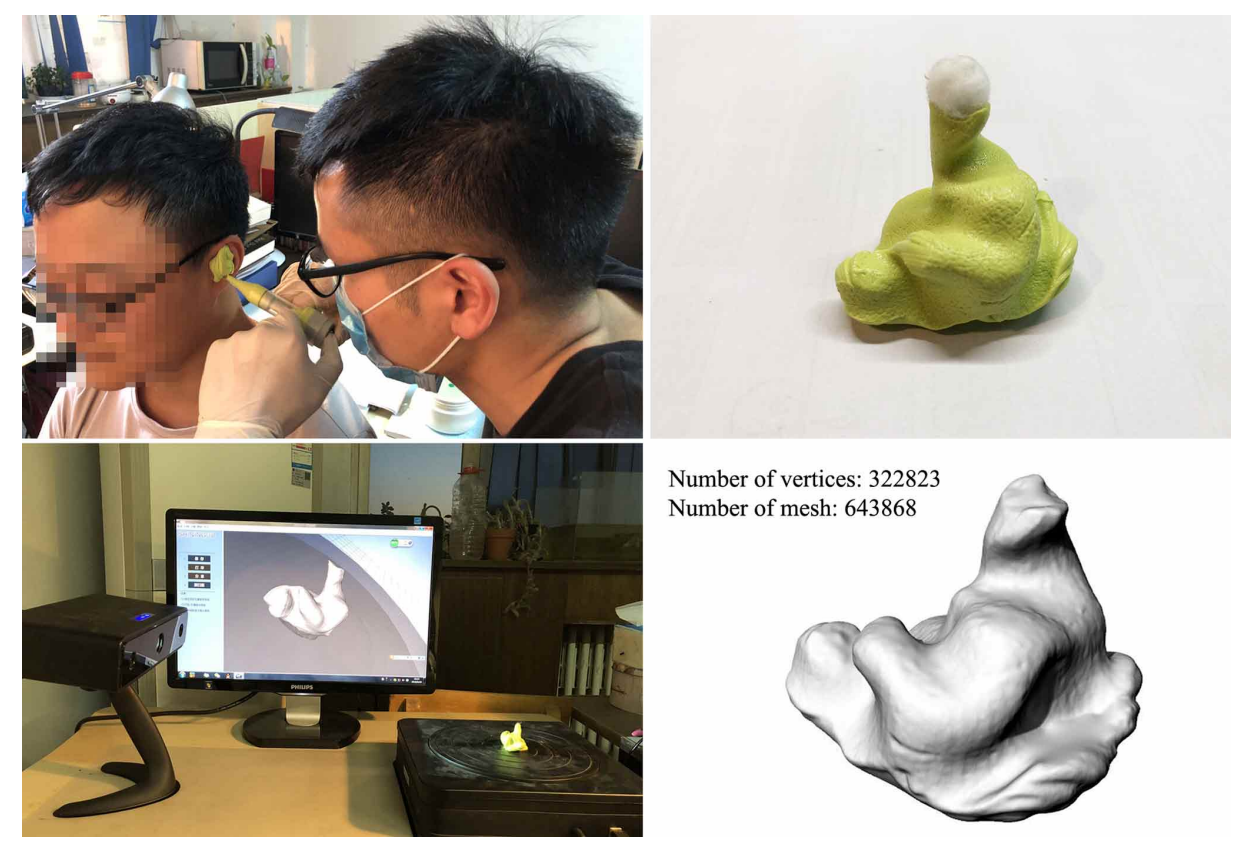

Fig. 1. Collect and scan ear impressions. 
Data point extraction and surface reconstruction. In our previous study (Zhu et al.), the 3D coordinates of eleven characteristic points for each 3D model were extracted (Fig. 2A). In order to classify the shapes of the auricular concha, the same number and characteristics of data points of the auricular concha were extracted from all of the scanned 3D models, that is, all of the 3D models were reconstructed into surfaces that have the same topology. The steps that involve data point extraction and surface reconstruction are as follows:

1. the characteristic contours of the auricular concha are extracted from the 3D model of the outer ear based on the characteristic points (Figs. 2A and 2B);

2. the characteristic contours of the auricular concha are reconstructed as first order curves with $N$ points (Fig. 2C) with a maximum deviation from the points of less than $0.01 \mathrm{~mm}$;

3. the points of the reconstructed characteristic contours are numbered and sorted, and then the curve of the auricular concha in the $\mathrm{V}$ direction is generated in accordance with two or three specific points and in a specific order (Fig. 2D);

4. the normal direction of the curves is set to be the same so that all of the curves start from a point located at the edge of the ear canal opening and end at a point on the outer contours of the auricular concha (Fig. 2E);

5. each curve of the concha in the $\mathrm{V}$ direction is reconstructed as a first order curve with $n$ points (Fig. $2 \mathrm{~F}$ ), and then the coordinates $(x, y, z)$ of the data points are converted into a text file; and

6. using the NURBS surface interpolation algorithm, all of the models of the auricular concha are reconstructed to have the same NURBS topology in consideration of the data points extracted in Step (5).

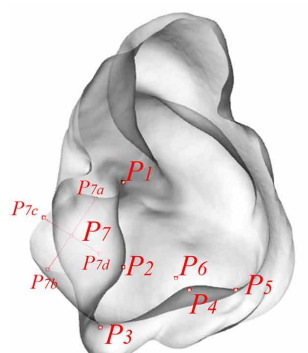

A

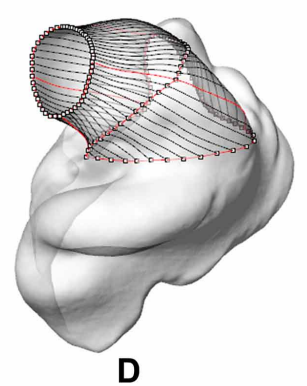

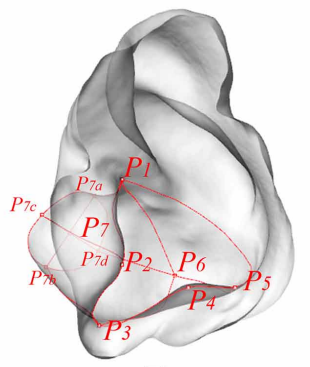

B

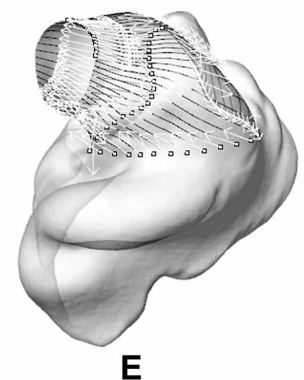

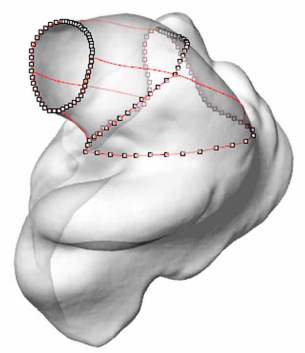

C

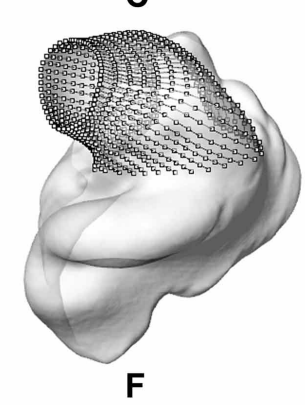

Fig. 2. Extract the data points of auricular concha from 3D ear impressions: (A) and (B) extracted the characteristic contours of concha in the $U$ direction; (C) reconstructed the characteristic contours of auricular concha in the $U$ direction; (D) generated the curves of auricular concha in the $V$ direction; (E) set the normal direction of curves; $(\mathrm{F})$ reconstructed the curves and extracted the data points. 
4. The best cluster is selected from each iteration. A total of 21 final clusters are calculated, when the algorithm is executed on a dataset of the seven samples. Four parameters, labeled as $a, b, c$, and $d$ are calculated to select the optimum cluster from each iteration by considering the deviations among the samples in each cluster. $a$ is the mean value of the sum of the distances from the points of all of the samples to their corresponding centroid points in a cluster. $b$ is the standard deviation of $a . c$ is the maximum mean value of the sum of the distance from each point to its corresponding centroid point in a cluster. $d$ is the maximum distance of all $\mathrm{L}_{j, h}$. The four parameters are calculated by using Equations (1) to (4), respectively.

$$
a=\frac{1}{N \times n} \sum_{j=1}^{n} \sum_{h=1}^{N} L_{j, h}
$$

$$
b=\sqrt{\frac{1}{N \times n-1} \sum_{j=1}^{n} \sum_{h=1}^{N} L_{j, h}}
$$

$$
c=\max _{j \in(1, n)} \frac{1}{N} \sum_{h=1}^{N} L_{j, h}
$$

$$
d=\max _{h \in(1, N), j \in(1, n)} L_{j, h}
$$

$$
(h \in(1, n)) \quad \bar{P}_{j}
$$

$(j \in(1, N))$

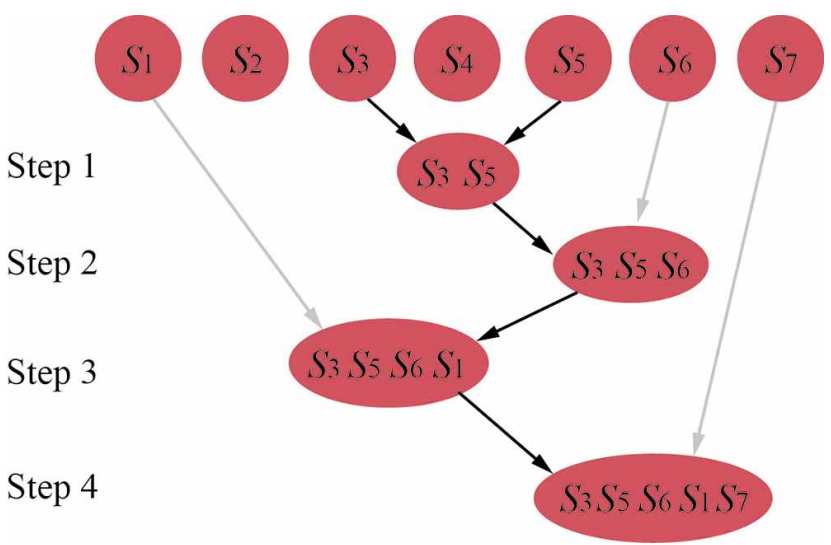

Fig. 3. Dendrogram of modified hierarchical clustering algorithm.
Experimental verification. The design for an OTC hearing aidis modeled by using Rhinoceros 5.0 (Robert McNeel \& Assoc Inc., Settle, WA, USA) based on the calculated results of the average shapes in this study. Furthermore, the 3D model was printed by using a 3D printer (MOSTFUN, China) with an accuracy of $0.1 \mathrm{~mm}$ and thermoplastic polyurethane (TPU) which is an elastic material. Then, a wear trial is used to determine the wear comfortable and the slip resistance of the hearing aid.

Meanwhile, in order to carry out computational and experimental testing of the stress pressure between the concha and the hearing aids, a simulation test is performed by ABAQUS 6.14 (SIMULA Inc., USA).

\section{RESULTS}

All of the 3D models of the auricular concha were converted into bicubic NURBS surfaces with the same topological structure based on the extraction results in terms of the 795 data points. The figure 4 is an example of a reconstructed surface which is composed of 795 data points.
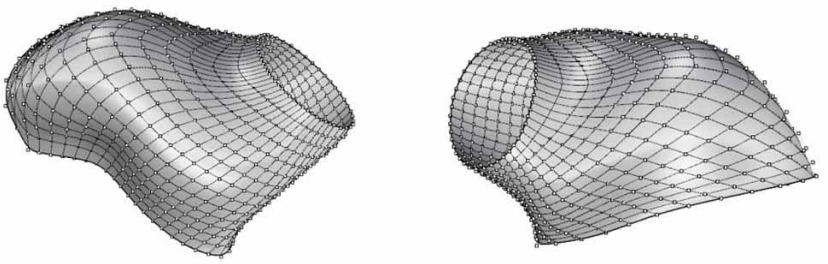

Fig. 4. Reconstructed surface of auricular concha.

Ji et al. indicated that the shape and dimensions of earphones or hearing aids mainly depend on the shape and dimensions of the auricular concha, and the characteristic points $\mathrm{P}_{1}, \mathrm{P}_{2}, \mathrm{P}_{3}, \mathrm{P}_{4}, \mathrm{P}_{5}, \mathrm{P}_{6}, \mathrm{P}_{7 \mathrm{a}}, \mathrm{P}_{7 \mathrm{~b}}, \mathrm{P}_{7 \mathrm{c}}$, and $\mathrm{P}_{7 \mathrm{~d}}$ (Fig. 2A) play an important role in the ergonomic design of ear-related products. Hence, the distance threshold values between each corresponding characteristic point and the remaining 785 data points were set separately in the processing of hierarchical clustering algorithm. Table I shows the distance threshold values for each characteristic point and the remaining 785 points.

According to the modified hierarchical clustering algorithm, all of the 305 samples (after removing three outliers) are classified into 29 clusters (Table II). The highest proportion $(21.4 \%$ of the total) is found in the cluster labelled as No. 1. The total proportion is $76.2 \%$ from Nos. 1 to 10. 
Table I. Distance thresholds (measurements in $\mathrm{mm}$ ).

\begin{tabular}{lcccccccccc}
\hline Points & $P_{1}$ & $P_{2}$ & $P_{4}$ & $P_{5}$ & $P_{6}$ & $P_{7 a}$ & $P_{7 b}$ & $P_{7 c}$ & $P_{7 d}$ & $P_{785}$ \\
\hline Values & 3.5 & 3.6 & 4.3 & 4.6 & 4.9 & 4.8 & 4.8 & 4.9 & 4.6 & 5.5
\end{tabular}

Table II. Clustering results (measurements in mm).

\begin{tabular}{|c|c|c|c|c|c|c|}
\hline Cluster & $T L$ & $A T L$ & $C W$ & $H_{E_{C O}}$ & $W_{E C O}$ & $P^{*}(\%)$ \\
\hline No. 1 & 17.2 & 16.6 & 16.3 & 9.3 & 7.1 & 21.4 \\
\hline No. 2 & 15.4 & 15.7 & 15.2 & 9.2 & 7.1 & 10.4 \\
\hline No. 3 & 16.9 & 15.0 & 15.6 & 9.0 & 7.2 & 9.7 \\
\hline No. 4 & 19.3 & 16.9 & 18.1 & 9.9 & 8.0 & 7.1 \\
\hline No. 5 & 16.7 & 15.8 & 16.9 & 9.5 & 7.3 & 6.8 \\
\hline No. 6 & 17.4 & 15.9 & 17.0 & 9.6 & 6.7 & 4.9 \\
\hline No. 7 & 16.0 & 15.1 & 14.7 & 9.2 & 7.0 & 4.9 \\
\hline No. 8 & 17.4 & 16.4 & 18.1 & 9.4 & 7.2 & 3.9 \\
\hline No. 9 & 17.6 & 15.1 & 16.6 & 9.7 & 7.6 & 3.9 \\
\hline No. 10 & 17.4 & 16.4 & 17.5 & 9.7 & 7.8 & 3.2 \\
\hline No. 11 & 17.1 & 17.1 & 16.2 & 10.2 & 7.7 & 2.3 \\
\hline No. 12 & 15.6 & 15.1 & 16.3 & 9.4 & 7.0 & 1.9 \\
\hline No. 13 & 18.1 & 16.3 & 15.2 & 9.6 & 7.0 & 1.6 \\
\hline No. 14 & 16.0 & 16.2 & 16.7 & 8.7 & 7.1 & 1.3 \\
\hline No. 15 & 17.1 & 17.5 & 14.8 & 7.5 & 7.4 & 1.6 \\
\hline No. 16 & 17.2 & 17.4 & 16.6 & 10.0 & 8.2 & 1.3 \\
\hline No. 17 & 17.3 & 16.9 & 16.4 & 9.4 & 7.2 & 1.6 \\
\hline No. 18 & 16.9 & 17.9 & 18.0 & 9.9 & 7.9 & 1.3 \\
\hline No. 19 & 19.3 & 17.7 & 19.0 & 10.3 & 7.7 & 1.6 \\
\hline No. 20 & 15.5 & 14.4 & 14.7 & 8.3 & 6.5 & 1.3 \\
\hline No. 21 & 19.5 & 18.3 & 16.5 & 11.3 & 8.9 & 1.0 \\
\hline No. 22 & 17.5 & 16.1 & 14.2 & 9.5 & 5.9 & 1.0 \\
\hline No. 23 & 17.7 & 14.8 & 16.8 & 8.9 & 6.9 & 0.6 \\
\hline No. 24 & 17.2 & 17.3 & 16.6 & 9.5 & 8.0 & 0.6 \\
\hline No. 25 & 16.7 & 14.8 & 17.4 & 9.2 & 6.9 & 1.0 \\
\hline No.26 & 16.7 & 17.1 & 19.3 & 8.7 & 7.3 & 0.6 \\
\hline No. 27 & 19.5 & 17.4 & 15.3 & 10.1 & 7.2 & 0.6 \\
\hline No. 28 & 18.2 & 15.0 & 16.3 & 8.8 & 7.2 & 0.6 \\
\hline No. 29 & 16.6 & 14.2 & 16.6 & 8.8 & 6.5 & 0.6 \\
\hline$A l l_{\text {s. wonlan }}$ & 17.1 & 15.7 & 16.5 & 9.6 & 7.5 & \\
\hline$A l l_{\text {fomal } \rho \mathrm{s}}$ & 16.3 & 15.0 & 15.3 & 9.0 & 6.1 & \\
\hline$A l l_{m a l o c}$ & 17.5 & 16.2 & 16.9 & 9.3 & 7.1 & \\
\hline
\end{tabular}

*P: Proportion of samples of each cluster.

Based on the average coordinates of the 795 data points of all of the samples in each cluster, the average shape of the auricular concha for each cluster was generated by using the NURBS surface interpolation algorithm. Fig. 5 shows the average shape of each cluster. Fig. 6 shows the average shape of all 308 samples, all 141 females and 167 males, respectively. Fig. 7 is the comparison of average shape between clusters Nos. 8 and 9, and Nos. 10 and 11. Fig. 8 shows the deviation analysis between the average shapes of auricular concha for all samples and cluster No. 5. The maximum deviation is only $1.3 \mathrm{~mm}$. Table II presents the characteristic dimensions of each cluster, such as the length of the tragus (TL), length of the antitragus

(ATL), width of the concha (CW), and height (HECO), and width (WECO) of the ear canal opening.
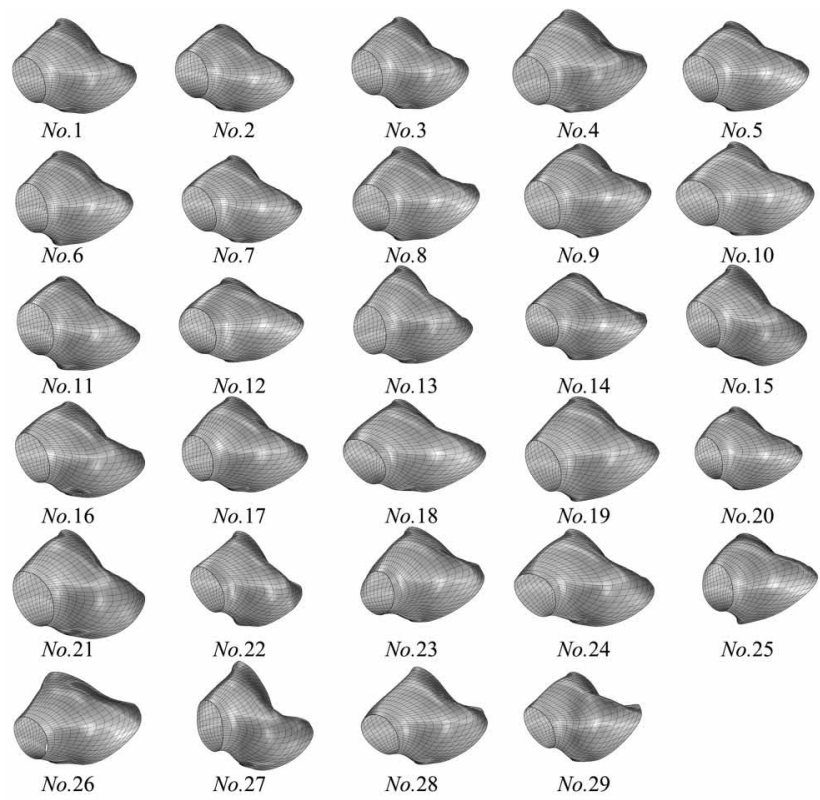

Fig. 5. Average shape of auricular concha in each cluster.

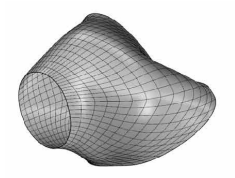

Allsamples

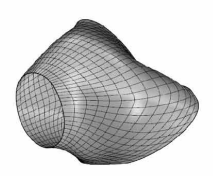

Allfemales

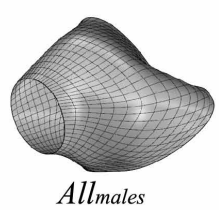

Fig. 6. Average shapes of auricular concha for all 308 samples, 141 females and 167 males, respectively.

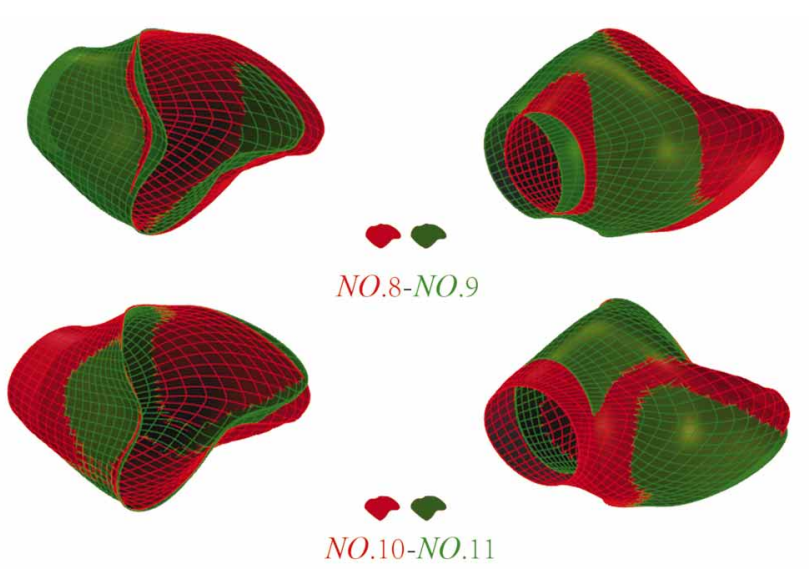

Fig. 7. Comparison of average shape between Nos. 8 and 9, and Nos. 10 and 11. 

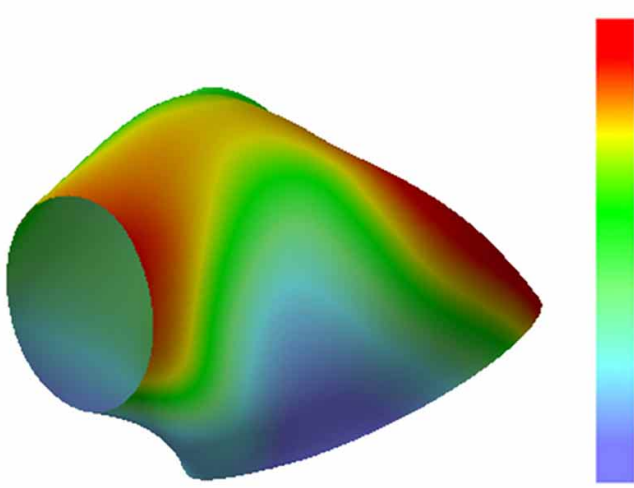

$1.3 \mathrm{~mm}$
$14.30 \%$
$0.52 \mathrm{~mm}$
$14.28 \%$
$0.282 \mathrm{~mm}$
$14.28 \%$
$0 \mathrm{~mm}$
$19.05 \%$
$-0.23 \mathrm{~mm}$
$19.05 \%$
$-0.476 \mathrm{~mm}$
$19.03 \%$
$-0.989 \mathrm{~mm}$

Fig. 8. Deviation analysis between the average shapes of concha for all samples and cluster No. 5 .

The shape of OTC hearing aid of No.6 was designed and printed based on the average shape of No. 6. Four participants of No. 6 were selected to wear the printed model to validate the robustness of the clustering method (Fig. 9A). The results showed that the shape of the printed OTC Hearing aid approximates the real auricular concha of the participants. The participants were then required to wear the printed model for $1 \mathrm{~h}$ and did not experience pain or discomfort. At the same time, four participants were randomly selected from the other clusters to use the No.6 printed model as shown in Fig. 9B, and the results present a striking contrast to that in Fig. 9A. Subsequently, the six participants of No. 6 ran on a treadmill at different speeds $(4,6,8,10,12,14$, and $16 \mathrm{~km} / \mathrm{h})$ and skip in different ways (e.g., basic, alternate foot, and crisscross jumping) to determine the slip resistance of the models (Fig. 10). The results showed that the model does not slip in the two conditions.

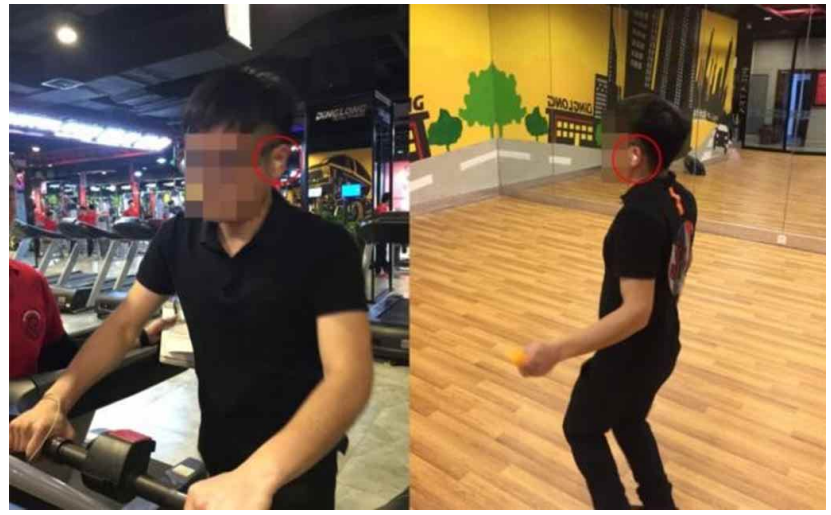

Fig. 10. Determining slip resistance of OTC hearing aid.

Fig. 11 shows the stress pressure distribution between the outer ear of participant from No. 6 and OTC hearing aid designed based on the average shape of No. 6. The stress distribution is uniform, and the maximum pressure is only $0.202 \mathrm{MPa}$. As a comparison (Fig. 12), the stress distribution fluctuates and the maximum pressure increases significantly when the participant from No. 6 wears the OTC hearing aid with a design based on the average shape of other clusters.

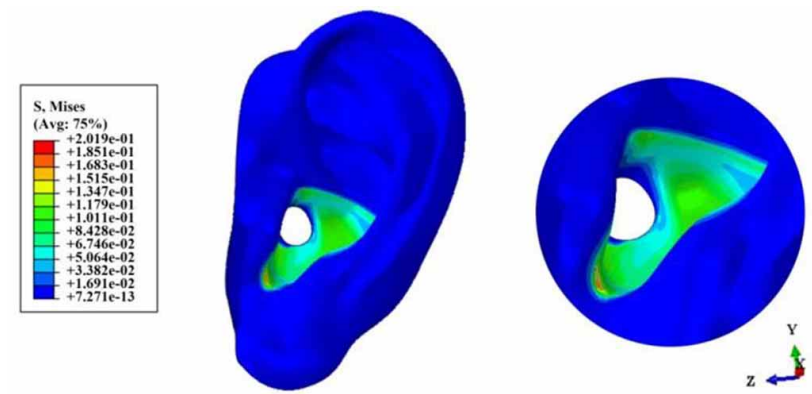

Fig. 11. Contact stress distribution No. 6.
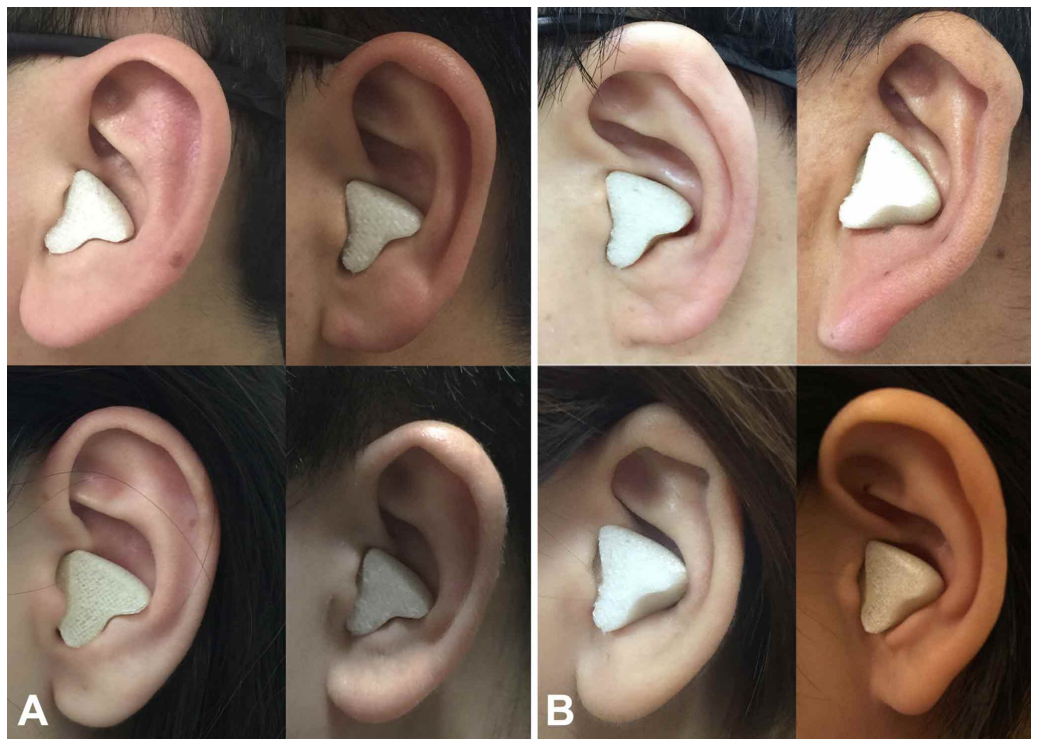

Fig. 9. Determining wear comfort and fit of OTC hearing aid.
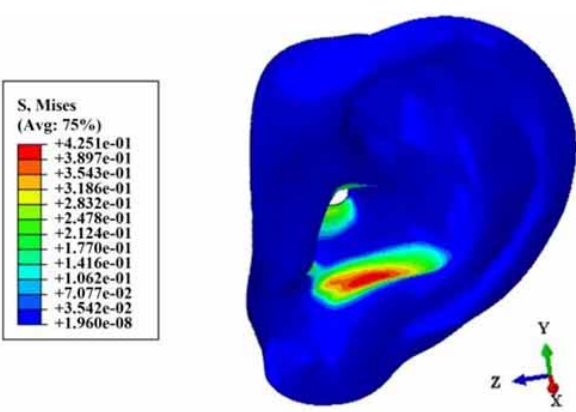

Fig. 12. Contact stress distribution-other clusters. 


\section{DISCUSSION}

The previous studies mainly determined the sexual dimorphism and bilateral asymmetry of auricular concha using the its characteristic dimensions, for instance, conchal length and width. But, these univariate measures of conchal size in the literature have limited applicability for reconstruction and rectification of a deformed ear, and particularly for the ergonomic design of hearing aid. Because, a small difference in characteristic dimensions of auricular concha does not mean a small difference in shape. This study therefore focuses on the difference in shape and different classifications of the auricular concha among young Chinese adults who are 18 - 28 years old. As such, the data can act as a useful database of the scanned shapes of the auricular concha of this specific population and used for the ergonomic design of OTC hearing aid for this cohort.

All of the collected conchal models are reconstructed into bicubic NURBS surfaces with the same topological structure based on the extraction results in terms of the 795 data points. On the basis of 795 data points of each sample, the 305 samples (after removing three outliers) are classified into 29 clusters by a modified hierarchical clustering algorithm. The average shapes of auricular concha for each cluster are calculated based on the average coordinates of the 795 data points of all of the samples in each cluster (Fig. 5). Meanwhile, the average shapes of all samples, all females, and all males are generated, respectively (Fig. 6). As shown in Fig. 5, the average shapes of auricular concha between each cluster are significantly difference, as well as the characteristic dimensions between each cluster. For example, the maximum deviation between TL of all clusters is $4.1 \mathrm{~mm}$ in cluster No. 21 and No. 2, that between CW of all clusters is $4.5 \mathrm{~mm}$ in cluster No. 26 and No. 15, and that between ATL of all clusters is $3.9 \mathrm{~mm}$ in cluster No. 21 and No. 20. The deviations of the related dimensions for Nos. 8 and 9 , and Nos. 10 and 11 are all negligible (Table II). However, significant deviations are found in each of the average shapes as shown in Fig. 7. Therefore, univariate measures of the auricular concha cannot adequately characterize the differences among the shapes of the auricular concha, so information of the entire shape should be taken into account during classifying the shape of the auricular concha.

As shown in Fig. 6 and Table II, the average shapes of auricular concha for all males and all samples are significantly larger than that for all females, as well as the characteristic dimensions. In worthwhile adding that, the female participants account for a large proportion in the clusters with small dimensions and shapes. The average shape of auricular concha for all samples is similar to the average shape of auricular concha for cluster No. 5 (Fig. 8), but the number of samples in cluster No. 5 accounts for only $6.8 \%$ (Table II) of the total samples. It indicates that OTC hearing aids designed based on the average conchal shapes of all samples cannot meet the needs of most people. Ideally, customized OTC hearing aids provide the best fit because they accommodate the conchal shape of individuals. However, they are also expensive and not suitable for mass production. Hence, to take both production convenience and the fit of most users into consideration, a number of shape systems for mass customization of custom-fit OTC hearing aids should be developed. The experimental results (Figs. 9 - 12) of present study show that the average shape of auricular concha obtained as per the cluster is capable of representing the common geometric properties of their corresponding members, and could thus be used as a reference in designing mass-customized OTC Hearing aids.

However, as with all studies, there are limitations and the cohort of Chinese 18 to 28 years old used as the sample in this study prevents the generalization of the results to a more wider population. It is recommended that future studies investigate a wider population, such as those who are younger than 18 years or a more mature population in the Chinese context. Moreover, an algorithm can be developed to categorize the participants into a smaller number of clusters, with the ability to still classify a large proportion of the samples into one of the clusters.

\section{CONCLUSIONS}

In conclusion, this study provides detailed information about the shape of normal auricular concha among young Chinese adults in an age group of 18- 28 years. The result in this study is superior to conventional methods that rely on sparse results for morphological analysis because it takes into account the intricate geometric shape of the auricular concha. The average shapes of each cluster generated in the present study could serve as a specific and useful database for the quantitative description of conchal morphometry in young Chinese adults. These intuitive data can be utilized in the diagnosis of congenital anomalies, ear constructive plastic surgeries, and particularly in ergonomic design of OTC hearing aids.

ACKNOWLEDGEMENTS. This study was supported by the National Natural Science Foundation of China (Grant number 52005498); the Fundamental Research Funds for the Central Universities (Grant number 2020SK15). The authors would like to thank the participants who volunteered for this study. 
ZHU, Z.; YAO, J.; CAO, B.; ZHOU, K. \& JI, X. Análisis estadístico de la forma de la concha auricular para la personalización masiva de audífonos de venta libre. Int. J. Morphol., 39(6):1655-1662, 2021.

RESUMEN: Actualmente no se dispone de datos específicos de la forma de la concha auricular. Por lo tanto, este estudio construyó un marco para analizar estadísticamente la forma de ella a partir de una base de datos de imágenes escaneadas en 3D. Los modelos 3D de la concha auricular de 308 participantes del estudio se convirtieron en superficies NURBS compatibles generadas a través de 795 puntos de datos para realizar un análisis estadístico requerido. Posteriormente, la forma de la concha auricular de los participantes se agrupó en 29 grupos con un algoritmo de agrupamiento jerárquico modificado. Finalmente, se llevó a cabo una prueba de uso y una prueba de simulación para validar la comodidad de uso de unos audífonos OTC diseñados en función de la forma promedio de cada grupo. Los resultados experimentales mostraron que la forma promedio obtenida de la concha auricular, según el grupo, es capaz de representar las propiedades geométricas comunes de sus miembros correspondientes y, por lo tanto, podría usarse como referencia en el diseño de audífonos OTC personalizados en masa. El método de este estudio es superior a los métodos convencionales que se basan en resultados escasos para el análisis de forma, porque tiene en consideración la intrincada forma geométrica de la concha auricular. La descripción cuantitativa de la morfometría de la concha auricular será beneficiosa para los cirujanos plásticos y para el diseño ergonómico de productos relacionados con el oído.

PALABRAS CLAVE: Morfometría Conchal; Agrupación de formas; Audífonos de venta libre; Personalización en masa.

\section{REFERENCES}

Ahmed, A. A. \& Omer, N. Estimation of sex from the anthropometric ear measurements of a Sudanese population. Leg. Med., 17(5):313-9. 2015.

Alexander, K. S.; Stott, D. J.; Sivakumar, B. \& Kang, N. A morphometric study of the human ear. J. Plast. Reconstr. Aesthet. Surg., 64(1):41-7, 2011.

Coward, T. J.; Scott, B. J.; Watson, R. M. \& Richards, R. Laser scanning of the ear identifying the shape and position in subjects with normal facial symmetry. Int. J. Oral. Maxillofac. Surg., 29(1):18-23, 2000.

Ellena, T.; Subic, A.; Mustafa, H. \& Pang, T.Y. A novel hierarchical clustering algorithm for the analysis of $3 \mathrm{D}$ anthropometric data of the human head. Comput. Aided Des. App., 15(1):25-33, 2018.

Fan, H.; Yu, S. H.; Chu, J. J.; Wang, M. C.; Chen, D. K.; Zhang, S.; Wang, W. Z.; Wu, T. \& Wang, L. Anthropometric characteristics and product categorization of Chinese auricles for ergonomic design. Int. J. Ind. Ergono., 69(1):118-41, 2019.

Ferrario, V. F.; Sforza, C.; Ciusa, V.; Serrao, G. \& Tartadlia, G. M. Morphometry of the normal human ear: a cross-sectional study from adolescence to mid-adulthood. J. Craniofac. Genet. Dev. Bilo., 19(4):226-33, 1999.

Han. K.; Kwon, H. J.; Choi, T. H.; Kim, J. H. \& Son, D. Comparison of anthropometry with Photogrammetry based on a standardized clinical Photographic technique using a cephalostat and chair. J. Cranio Maxill. Surg., 38(2):96-107, 2010

Jung, H. S. \& Jung, H. S. Surveying the dimensions and characteristics of Korean ears for the ergonomic design of ear-related products. Int. J. Ind. Ergon., 31(6):361-73, 2003.
Ji, X. M.; Zhu, Z. H.; Gao, Z.; Bai, X. B. \& Hu, G. Anthropometry and classification of auricular concha for the ergonomic design of earphones. Hum. Factor Ergon. Man., 28:90-9, 2017.

Kang, H. J.; Hu, K. S.; Song, W. C.; Kwon, H. J.; Park, D. K.; Sohn, H. J.; Koh, K. S.; Han, S. H.; Paik, D. J.; Chung, R. H. \& Kim, H. J. Physical anthropologic characteristics of the auricle through the metric and nonmetric analysis in Korean young adults. Korean J. Phys. Anthropol., 19(4):255-65, 2006

Kumar, B. S. \& Selvi, G. P. Morphometry of ear pinna in sex determination. Int. J. Anat. Res., 4(2):2480-4, 2016

Lee, W.; Yang, X.; Jung, H.; Bok, I.; Kim, C.; Kwon, O. \& You, H. Anthropometric analysis of 3D ear scans of Koreans and Caucasians for ear product design. Ergonomics., 61(11):1480-95, 2018.

Liu, B. S. Incorporating anthropometry into design of ear-related products. App. Ergon., 39(1):115-21, 2008.

Purkait, R. \& Singh, P. Anthropometry of normal human auricle: a study of adult Indian men. Aesth. Plast. Surg., 31(4):372-79, 2007.

Purkait. R. Progression of growth in the external ear from birth to maturity: a 2-year follow-up study in India. Aesthetic Plast. Surg., 37(3):605-16, 2013.

Russo, E. G. Longitudinal study of anthropometric changes with aging in an urban Italian population. HOMO, 49(3):241-59, 1998

Sforza, C.; Grandi, G.; Binelli, M.; Tommasi, D. G.; Rosati, R. \& Ferrario, V. F. Age-and sex-related changes in the normal human ear. Forensic. Sci. Int., 187(1-3):110.e1-7, 2009.

Sharma, A.; Sidhu, N. K.; Sharma, M. K.; Kapoor, K. \& Singh, B. Morphometric study of ear lobule in northwest Indian male subjects. Anat. Sci. Int., 82(2):98-104, 2007.

Singhal, J.; Sharma, N.; Jain, S. K.; Budhiraja, V.; Rastogi, R.; Garg, R.\& Nafees, H. A study of auricle morphology for identification in Indians. Ann. Int. Med. Den. Res., 2(4):217-24, 2016.

Tatlisumak, E.; Yavuz, M. S.; Kutlu, N.; Asirdizer, M.; Yoleri, L. \& Aslan, A. Asymmetry, handedness and auricle morphometry. Int. J. Morphol., 33(4):1542-8, 2015

Wang, B.; Dong, Y.; Zhao, Y.; Bai, S. \& Wu, G. Computed tomography measurement of the auricle in Han population of north China. J. Plast. Reconstr. Aesthe.t Surg., 64(1):34-40, 2011.

Yu, J. F.; Lee, K. C.; Wang, R. H.; Chen, Y. S.; Fan, C. C.; Peng, Y. C.; Tu, T. H.; Chen, C. I. \& Lin, K. Y. Anthropometry of external auditory canal by non-contactable measurement. Appl. Ergon., 50:50-5, 2015.

Zhao, S. C.; Li, D. G.; Liu, Z. Z.; Wang, Y. B.; Liu, L.; Jiang, D. Y. \& Pan, B. Anthropometry growth study of the ear in a Chinese population. $J$. Plast. Reconstr. Aes.,71(4):518-23, 2018.

Zhu, Z. H.; Ji, X. M.; Gao, Z. \& Hu, G. A morphometric study of auricular concha in the population of young Chinese adults. Int. J. Morphol., 35(4):1451-8, 2017

Corresponding author:

Jun Yao

School of Architecture \& Design

China University of Mining and Technology

No. 1 Daxue Road

Xuzhou 221116

CHINA

E-mail: yaojun@cumt.edu.cn

Received: 08-08-2021

Accepted: 30-08-2021 